\title{
Erratum to: Cancer-associated myositis: a 35-year retrospective study of a monocentric cohort
}

\author{
Rossella Neri · Simone Barsotti • Valentina Iacopetti • \\ Giacomo Iacopetti · Pasquale Pepe · Anna d'Ascanio · \\ Antonio Gaetano Tavoni $\cdot$ Marta Mosca $\cdot$ Stefano Bombardieri
}

Published online: 2 February 2014

(C) Springer-Verlag Berlin Heidelberg 2014

\section{Erratum to: Rheumatol Int}

\section{DOI 10.1007/s00296-013-2910-1}

The second author's given and family names were published wrongly in the original publication of the article. His name was inadvertently swapped. The correct author name is Simone Barsotti.

The correct author group is given below.

Rossella Neri - Simone Barsotti · Valentina Iacopetti · Giacomo Iacopetti · Pasquale Pepe · Anna d'Ascanio · Antonio Gaetano Tavoni $\cdot$ Marta Mosca $\cdot$ Stefano Bombardieri

The online version of the original article can be found under doi:10.1007/s00296-013-2910-1.

R. Neri $(\bowtie) \cdot S$. Barsotti $\cdot$ V. Iacopetti $\cdot$ G. Iacopetti $\cdot$ P. Pepe

A. d'Ascanio - M. Mosca - S. Bombardieri

Rheumatology Unit, Azienda Ospedaliero-Universitaria Pisana,

Via Roma 67, 56126 Pisa, Italy

e-mail: rneri@int.med.unipi.it; r.neri@med.unipi.it

A. G. Tavoni

Immunoallergology Unit, University of Pisa, Pisa, Italy 